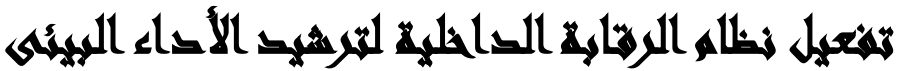

\section{[IY]}

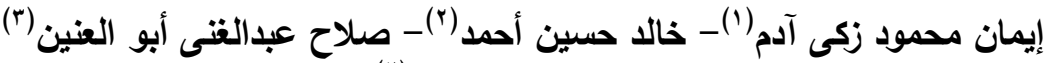

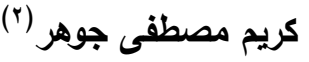

() وزارة التربية والتعليم r) كلية التجارة، جامعة عين شمس جمه كلية العلوم، جامعة عين

\section{(ll}

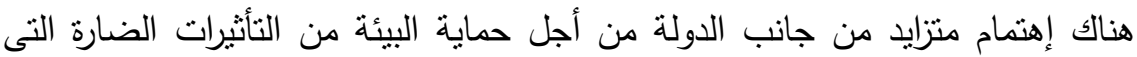

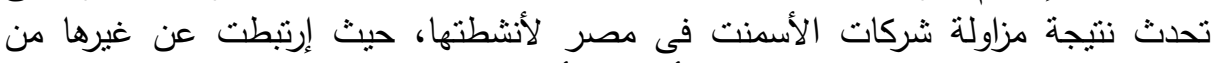

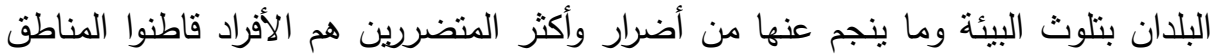

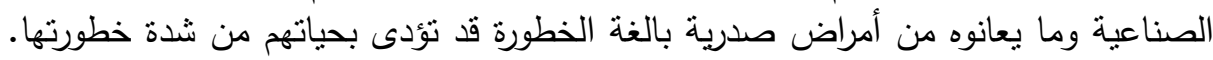

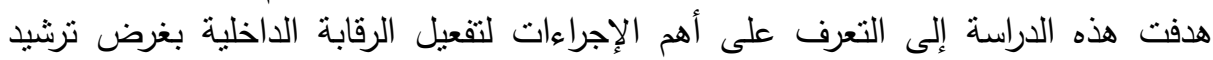

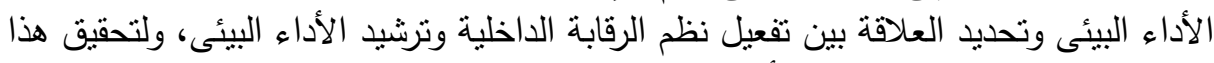

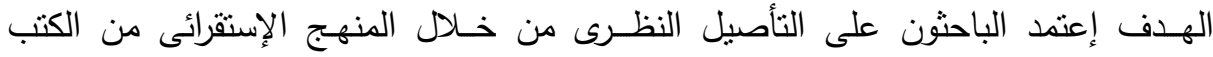

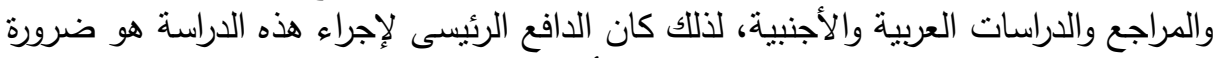

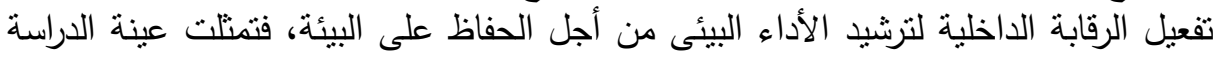

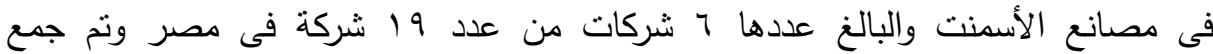

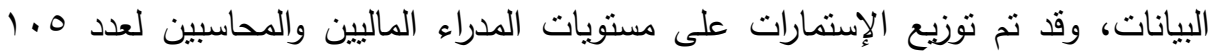
للمستويات المذكورة فى تلاتك الثركات محل الأن الدراسة.

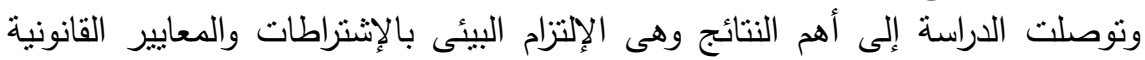

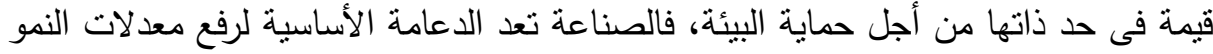

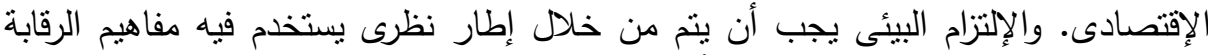

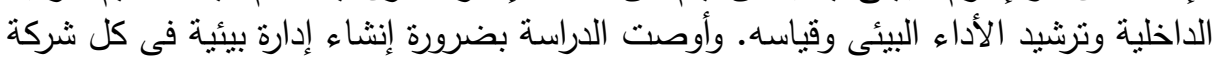
صناعية وذللك لمتابعة المعايير والثروط المسموح بها وذللك للحد من التلوث البيئى. 


\section{גation}

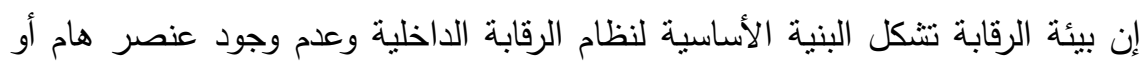

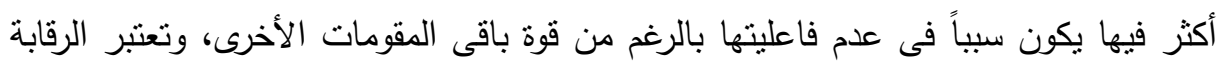

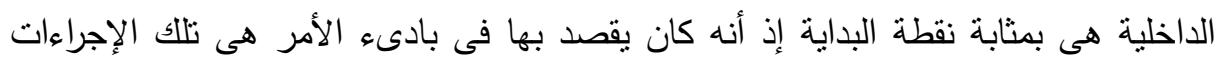

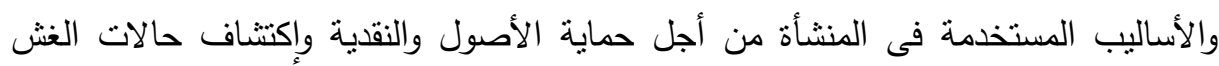

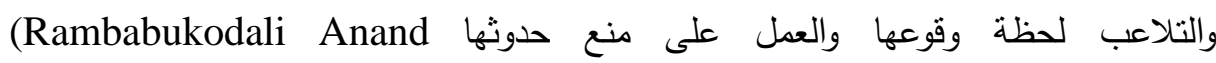
.Gurumurthy, 2009 ) هذا بالإضافة إلى أن موضوع البيئة أصبح هو واحد من أحد الموضوعات المهمة

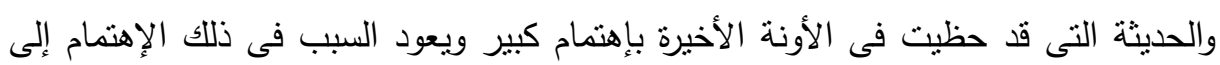

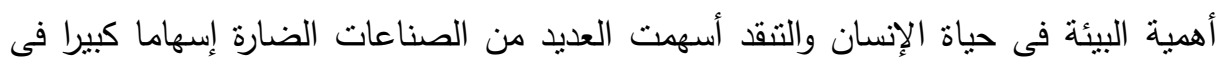

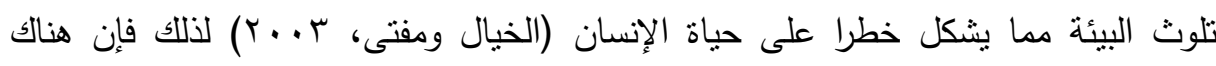

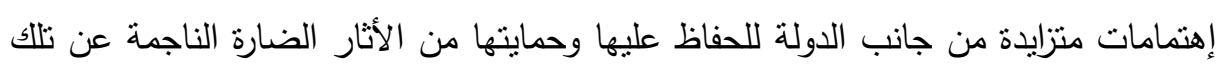

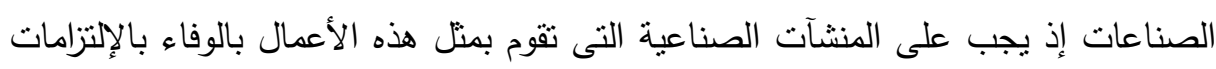

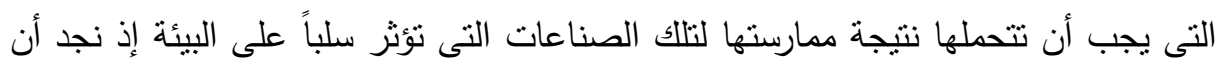

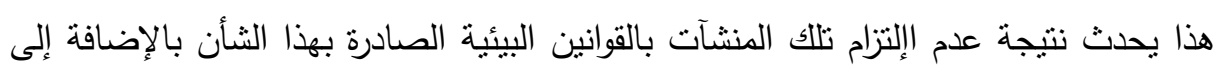

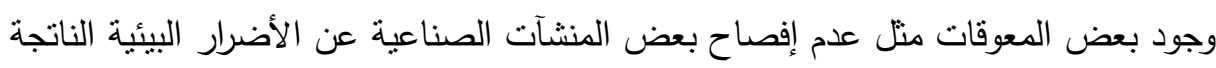

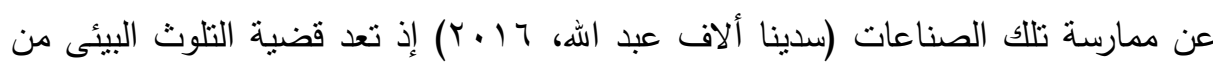

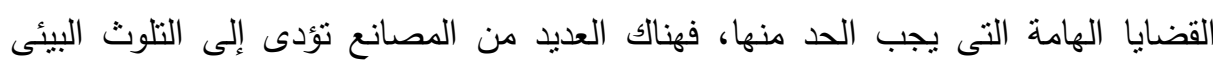

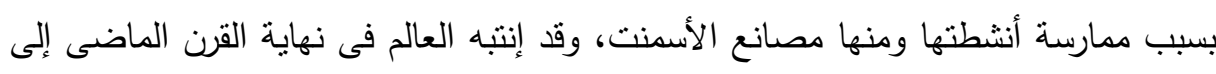

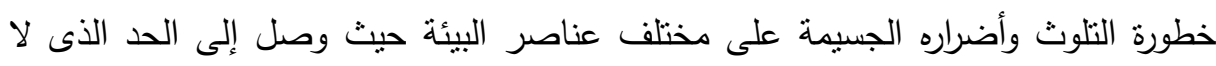

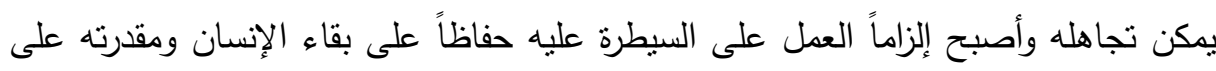

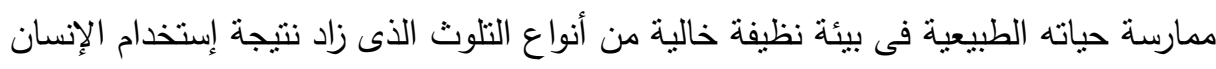

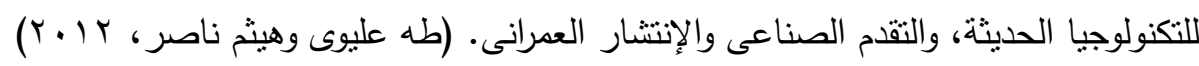




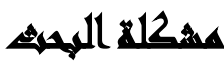

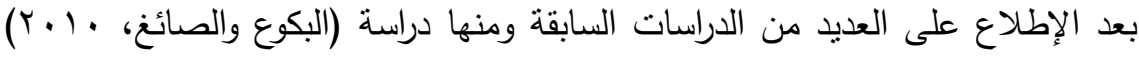

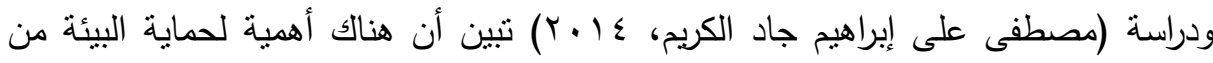

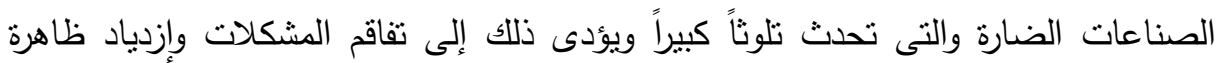

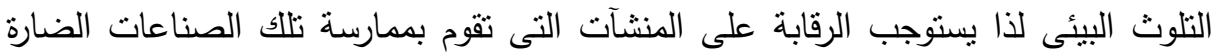

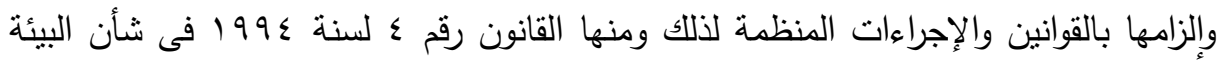
ولائحته التتفيذية، كما يجب أن نقوم الرقابة الداخلية بالإضافة إلى حماية البيئة من نالك الكاني

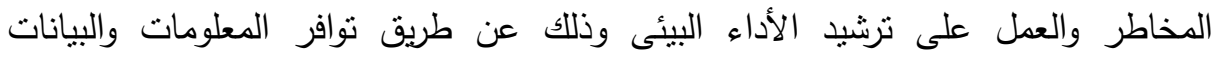

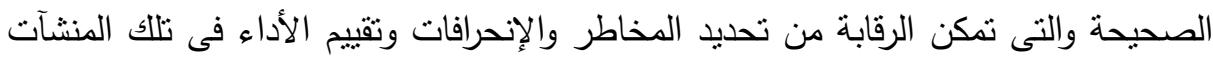

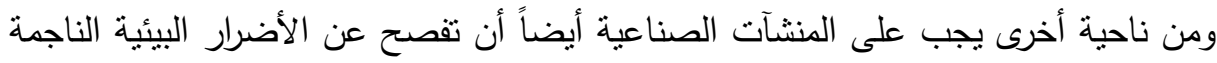

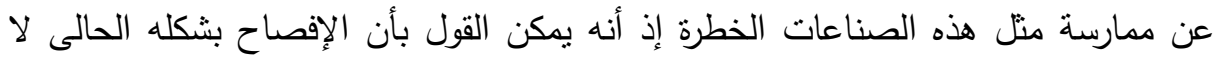

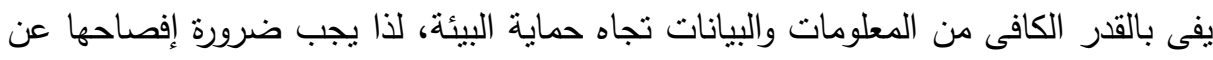

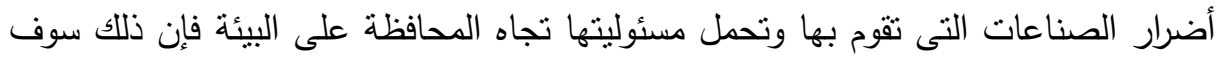
يحقق العديد من المنافع الإقتصادية.

\section{أسئلا المهيه}

ويستمد من السؤال الجوهرى عدة أسئلة فرعية وهى:

1. إما إكانية تفعيل نظام الرقابة الداخلية؟

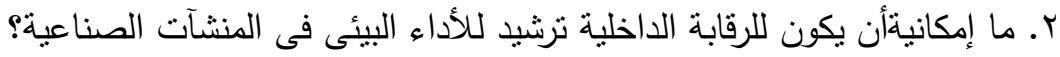

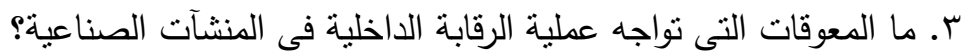

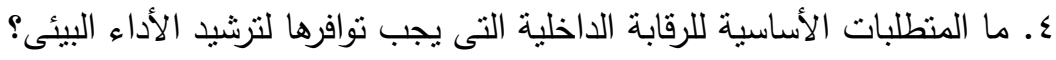




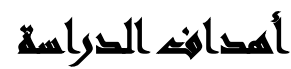

اللهدف الرئيسي: هو تفعيل نظام الرقابة الداخلية لترشيد الأداء البيئى من خلا عدة أهداف

$$
\text { فرعية وهى: }
$$

ا ـ توضيح المنطلبات الأساسية للرقابة الداخلية لترشد الأداء البيئى. r. وجود أليات جديدة فى نظام الرقابة الداخلية للعمل على تفعيلها.

r. العمل على حل المعوقات التى تواجه نظام الرقابة الداخلية .

؛. الحد من ظاهرة التلوث البيئى والعمل على القضاء عليها.

\section{هزوضر الكواسمات}

الفرض الأول: لا توجد علاقة جوهرية ذات دلالة إحصائية بين تفعيل نظم الرقابة الداخلية

$$
\text { وترشيد الأداء البيئى. - الفئ. }
$$

الفرض الثانى: لا توجد علاقة جوهرية ذات دلالة إحصائية بين فاعلية الرقابة الداخلية والمسئولية الإجتماعية.

الفرض الثالث: لا توجد علاقة جوهرية ذات دلالة إحصائية بين ترشيد الأداء البيئى والإهنمام بالمسئولية الإجتماعية. الفرض الرابع: لا توجد علاقة جوهرية ذات دلالة إحصائية بين فاعلية الرقابة الداخلية والإلتزام بقانون حماية البيئة.

\section{مورو الصراسما}

إقتصرت هذه الدراسة على شركات الأسمنت والبالغ عددها (7) شركات من عدد 19

$$
\text { شركة فى مصر . }
$$




\section{منهمبه التواسما}

تهدف تلك الدراسة لصياغة الإطار النظرى من خلال تجميع المادة العلمية ذات الصلة

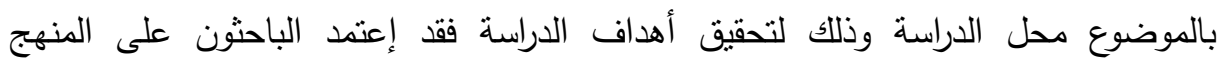

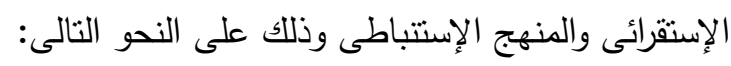

المنهج الإستقرائى: والذى يشمل (الكتب الدورية والمقالات العلمية، والمراجع العربية والأجنبية) ويتم ذلك من خلا إطار نظرى يستخدم فيه مفاهيم الرقابة الداخلية وترشيد الأداء البيئى وقياسه.

المنهج الإستتباطى: قامت الباحثون من خلال هذا المنهج بإختبار فروض الدراسة إحصائياً، وتطبيق الدراسة العملية بإستخدام إستمارة إستقصاء على عينة من شركات الأسمنت عن طريق أخذ عينة عشوائية من مجتمع الدراسة وقد إختصت بمن لديهم خبرة فى هذا المجال وصلة بالموضع محل الدراسة. ترجع أهية تلك الدراسة إلى إلزامية إحداث تطوير فى عملية الرقابة وأيضا سوف تفتح

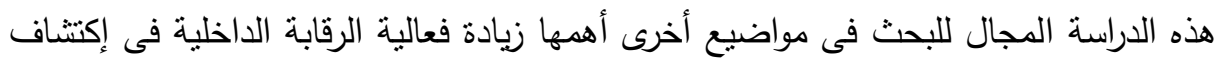

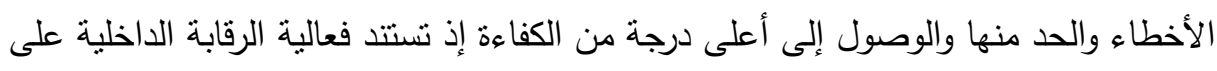
العمل الجيد بنظام الرقابة الداخلية وتتجلى أهمية تلك الدراسة من الناحيتين العلمية والعملية أهمية الدراسة العلمية: نظرا لأهمية الرقابة الداخلية لما تتناوله من كافة السياسات

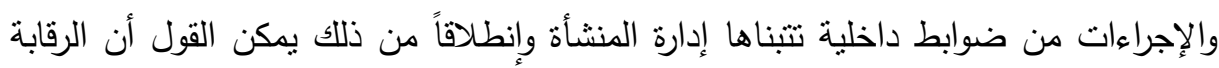
الداخلية تعمل على الحفاظ على البيئة وذللك من خلال إلزام تللك المنشآت بالقوانين والأنظمة. أهمية الدراسة العملية: إن موضوع حماية البيئة له بالغ الأهمية وذلك بعد إنتشار ظاهرة

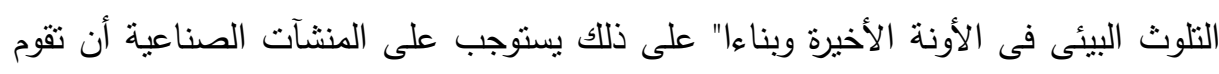
بمراعاة الأثار البئية الناجمة عن ممارستها لتلك الصناعة الأئ وناعات وذلك من أجل الحفاظ على البيئة 
وأيضا معرفة مدى التزام تللك المنشآت الصناعية بالقوانين واللوائح والتعليمات المنظمة لذلك

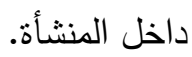

\section{كسطلحاهي التراسمة (المخاهيه)}

مفهوم الرقابة الداخلية: هى تلك الخطة التنظيمية وجميع الطرق والإجراءات والأساليب

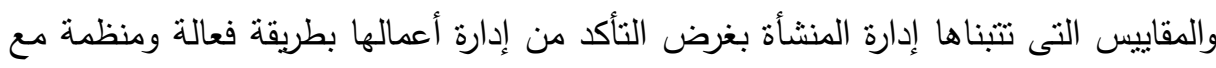

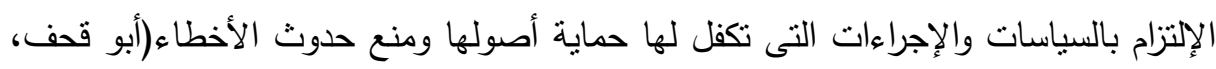

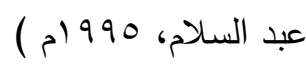

نظام الرقابة الاخلية: عرف نظام الرقابة الداخلية من قبل مجلس معايير الدحاسبة الدولية

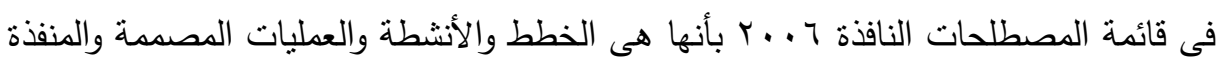
من قبل المعنيين بالقيام بهاوذلك وفق الأنظمة والتعليمات التى تحكم العملية الرقابية ومن يقع

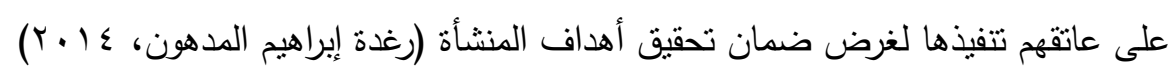

\section{الصوراسايت المايوية}

دراسة عمرو محمد خميس محمد ( • ( • ( ): بعنوان أثز تفعيل آليات حوكمة الثركات على مستوى الإفصاح البيئى الإختيارى. وهدفت الدراسة إلى الفصل بين منصبى كل من

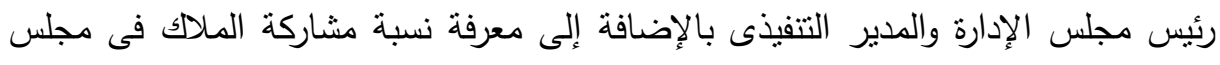

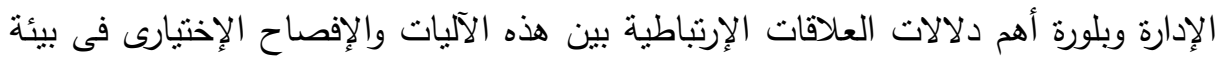

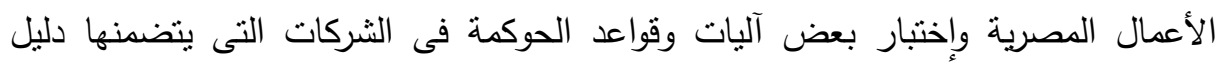

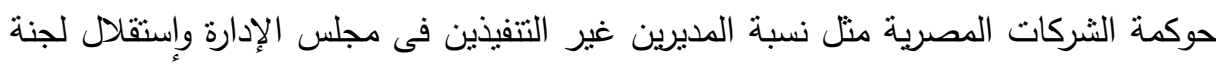

$$
\text { المراجعة. }
$$

نتائج الدراسة:

ا. تحقيق الثركات لأهدافها فى مجال تحسين أدائها البيئى وتحقيق مفهوم التتمية المستدامة

$$
\text { إنما يتوقف على تفعيل آليات حوكمة الثركات. }
$$

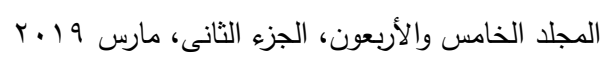


r. إن تفعيل آليات حوكمة الثركات يساعد الثركات فى إدارة الثركة بصورة جيدة وحماية كافة المصالح خارج وداخل الثركة.

توصيات الدراسة: ضرورة الربط بين كل من تفعيل آليات حوكمة الثركات وأثزها على مستوى ودى الإفصاح للرقابة الداخلية فى المنثآت الصناعية.

دراسة عادل البهلوان حميدان الطاهر (11 ( ب): بعنوان الإفصاح المحاسبي عن الأداء البيئى فى الثركة الأهلية للأسمنت بليبيا - دراسة إستطلاعية، دكنوراه. وهدفت تلأك

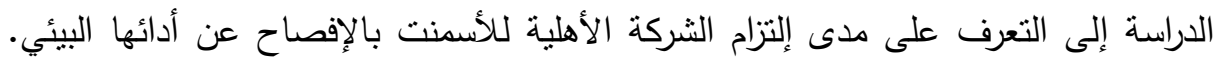
كما هدفت أيضا إلى إبراز المعوقات التى تحول دون قيام الثركة بالإفصاح عن أدائها البيئى. نتائج الدراسة: هناك العديد من المعوقات التى تحد من قيام الثركة الأهلية للأسمنت بالإفصاح عن أدائها البيئى وأبرز تلك المعوقات هى فلة التوعية للتعرف على متطلبات الأداء

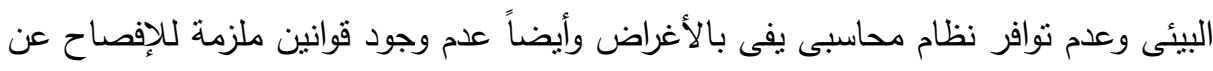

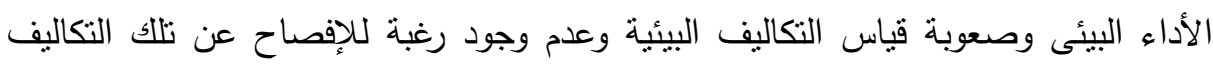
المتعلقة بالأضرار البيئية الناتجة عن عملياتها. توصيات الاراسة: منح المنشآت التى تحافظ على البيئة معاملة ضريبية مميزة من حيث الإعفاء أو التخفيض فى قيمة الضرائب المفروضة عليها وذلك تتجيعاً لها على حماية البيئة. دراسة ( Kathyayini, 2012 (بعنوان:

Corporate governance and environmental reporting: an Australian study. Vol. 12, Iss: 2

وهدفت هذه الدراسة إلى تحقيق العلاقة بين إعداد التقارير البيئية وبين حوكمة الشركات فى 2 أستراليا.

نتائج الدراسة: توصل الباحث عن طريق عدد من التقارير السنوية لعدد ... أشركة مدرجة

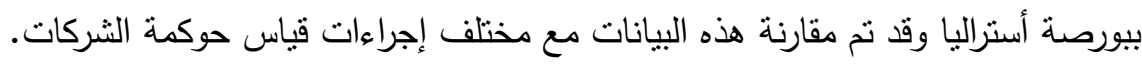
دراسة (Mousa Saleh, 2012) بعنوان:

Environmental Disclousurein Industrial Companies in Aqaba

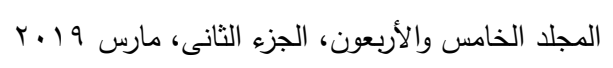


وهدفت تلك الدراسة إلى التعرف على الإفصاح البيئى فى الثركات الصناعية فى منطقة العقبة وأثز هذا الإفصاح على قدرة هذه الثركات فى الحصول على التمويل الازم وايضاً بيان علاقة الإفصاح المحاسبى البيئى بأرباح تلك الثركات. نتائج الدراسة: وجود علاقة بين الإفصاح المحاسبى البيئى وقدرة الثركات فى الحصول على الئى قروض ووجود علاقة بين الإفصاح المحاسبى البيئى وتعزيز القدرة التتافسية للمنشآت الإحسي الصناعية وعدم وجود علاقة بين الإفصاح المحاسبى البيئى وقيمة أرباح الثركات الصناعية. دراسة (Claudia, 2013) بعنوان:

A review of environmental monitoring and auditing in the context of risk: unveiling the extent of a confused relationship

وهدفت تلك الدراسة إلى تحسين الأداء فى المنظمات والثركات وايضاً إلى التقليل من المخاطر البيئية.

نتائج الاراسة: معرفة كيفية التقليل من المخاطر البيئية التى تواجهها المنظمات وعرض وتوصيف الرصد البيئى والمراجعة الداخلية. وهناك المزيد من الدراسات التى تم عرضها في منن الرسالة.

\section{الإطالر النظليه اللقراسمة}

تفعيل نظام الرقابة الداخلية: الرقابة الداخلية تشتمل على الخطة التظيمية وجميع الطرق

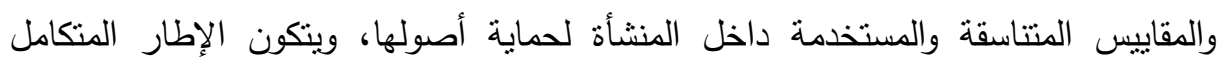

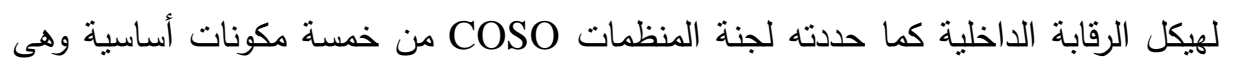

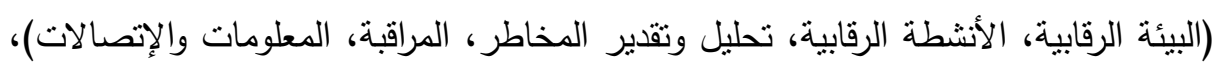

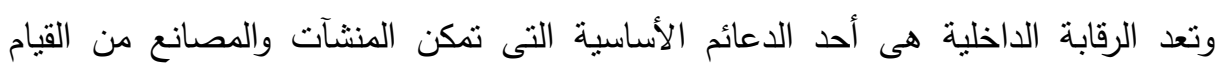

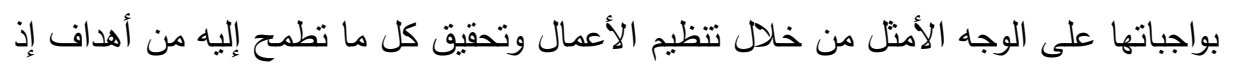

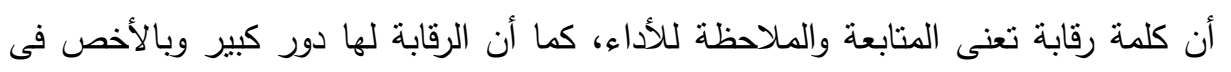

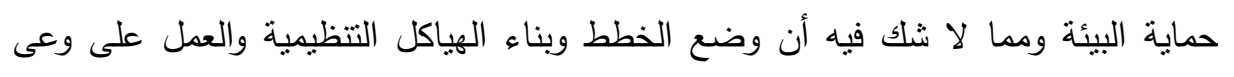
وتوجيه العاملين داخل المنشآت الصناعية لا يضمن أن كل شئ ينم على الوجه الأمتل لذاه

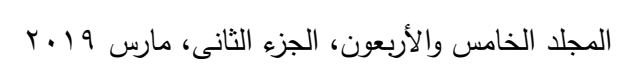


يجب التأكد من أن كل الأنشطة المتعلقة بالعمل سيتم أدائها حسب ما نم وضعه فى الخطة

$$
\text { (شاكر عبد الكريم هادى، } 991 \text { ()). }
$$

1- المحور الأول (محور المراقبة): وهى التى تعنى حماية الأصول والصالح العام عن طريق

$$
\text { إكتثاف الأخطاء. }
$$

r-المحور الثانى (توجيه الإدارة): ينم توجيه الإدارة إلى التدخل السريع لإتخاذ ما يلزم من

$$
\text { قرارات لتصحيح الأخطاء من أجل تحقيق الأهداف. }
$$

r-المحور الثالث (التقليل من الأخطاء أو منعها): ما يحتمل أن تكثثف عنه عملية الرقابة الداخلية من عناصر تلعب دوراً هاماً فى التقليل من الأخطاء وإكتثافها فور حدوثها: ماءها

لجنة حماية المنظمات COSO: هى لجنة تتكون من أعضاء الهيئات المهنية المعنية بالأمور المحاسبية والمالية للمنظمات، تأسست سنة 910 ام بدعم من المعاهد والهيئات

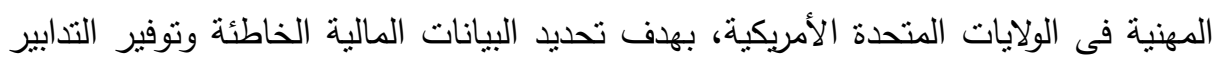
الوقائية عن تلك الأخطاء، وقد بينت هذه اللجنة أهمية الرقابة الداخلية فى شركات الأسمنت

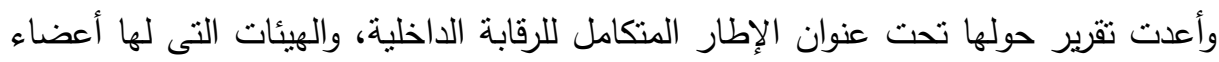
فى تلك اللجنة وهى:

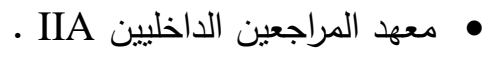
• • معهد المحاسبيين القانونيين الامريكيين AICPA. • جمعية المحاسبة الأمريكية AAA.

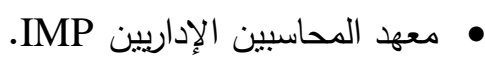
• معهد المحليين الماليين FEA. 


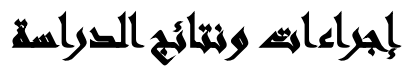

الإجراءات المنهجية للاراسة: إعتدت الباحثون على المنهج الإستقرائى الإستتباطى

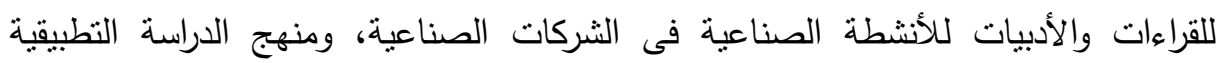

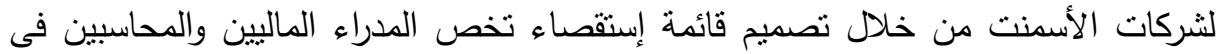

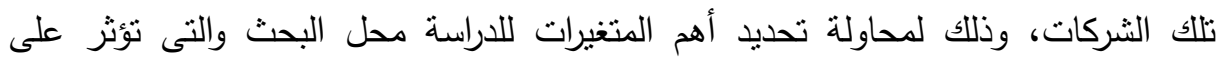

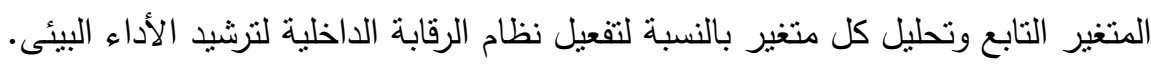
المتغير المستقل: تفعيل نظام الرقابة الداخلية.

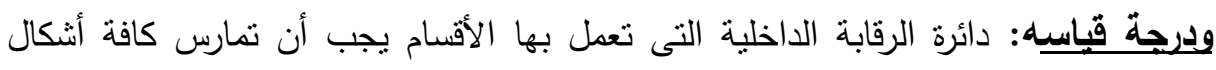

$$
\text { الرقابة من رقابة (إدارية - مالية - فنية - بيئية) }
$$

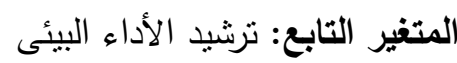

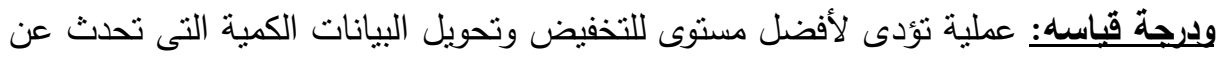
كمية النلوث الناتجة عن المنثآت الصناعية إلى وحدات نقدية.

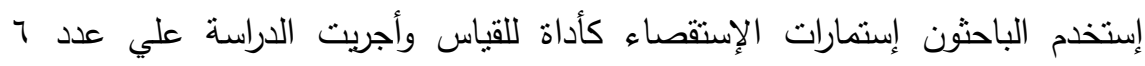

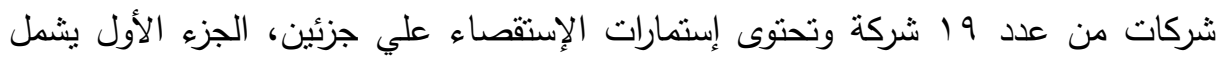

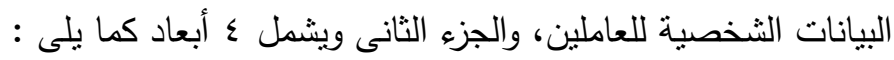
• إكانية تفعيل نظام الرقابة الداخلية. • • بمكن للرقابة الداخلية ترشيد الأداء البيئى في المنشآت الصناعية.

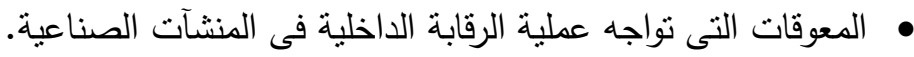

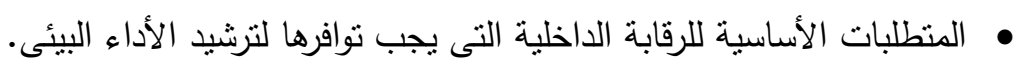

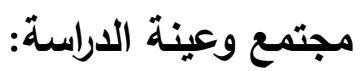
مجتمع الاراسة: يتمتل مجتمع الدراسة في العاملين بثركات الأسمنت. عينة الدراسة: تم اخذ عينة عشوائية من مجتمع الدراسة وتم إحتساب عددها طبقاً للمعادلة الآتية: 


$$
n=\frac{N \times p(1-p)}{\left.\left[N-1 \times\left(d^{2} \div z^{2}\right)\right]+p(1-p)\right]}
$$

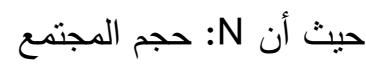
n : عينة الدراسة عندما يكون السحب بإرجاع والمجتمع كبير

Z

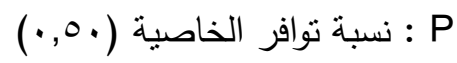

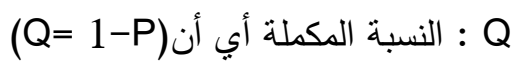

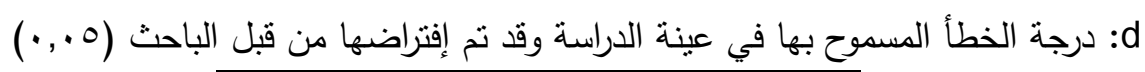
$83=\frac{105 \times 0.5(0.5)}{\left.\left[104 \times\left(0.05^{2} \div 1.96^{2}\right)\right]+0.5(0.5)\right]}$

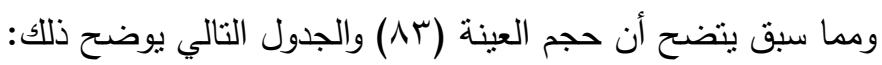
جدول (1): يوضح مجتمع وعينة الدراسة

\begin{tabular}{|c|c|c|}
\hline العينة|لمطلويـة & عدد الموظفين & إسم الثركة \\
\hline 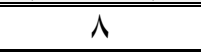 & 1. & حلوان \\
\hline 11 & $1 \varepsilon$ & طرة \\
\hline 11 & $1 \leqslant$ & السويس \\
\hline$r \varepsilon$ & $r$. & القومية \\
\hline $1 \varepsilon$ & 11 & مصر بني سويف \\
\hline 10 & 19 & أسكندرية بنى سويف \\
\hline$\Delta \Gamma$ & 1.0 & آلإجمالى \\
\hline
\end{tabular}
يوضح الجدول (r) توزيع عينة الدراسة البالغ عددها (r^) استمارة تم توزيعها على الثركات. 
جلول (ץ): بوضح مقياس ليكرت الخماسى

\begin{tabular}{|c|c|}
\hline الإتجاه & الفئة \\
\hline تميل الإجابات إلى (غبر موافق أبدا) & $1629-16 \ldots$ \\
\hline تميل الإجابات إلى (غير موافق) & r.09-1,1. \\
\hline تميل الإجابات إلى (محايد) & $r_{6} r_{q}-r_{67}$. \\
\hline تميل الإجابات إلى (موافق) & $\left.\varepsilon_{6}\right) 9-r_{6} \varepsilon \cdot$ \\
\hline تميل الإجابات إلى (مؤافق تماما) & $0_{6} \ldots-\varepsilon_{6} Y$. \\
\hline
\end{tabular}

المصدر: لرينس ليكرت ( 2013Likert, Rensis,)

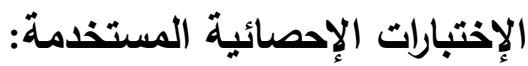

إختبار لإستمارة الإستقصاء: إختبار ألفا كرونباخ Cronbach's alpha لقياس ثبات وصدق

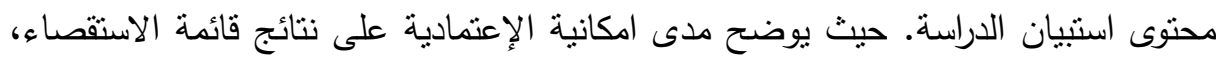

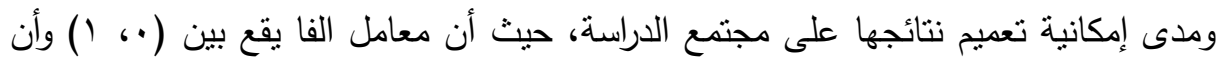

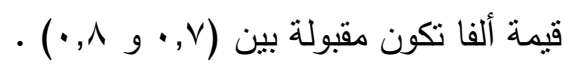

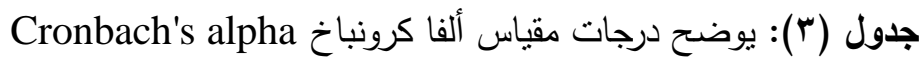

\begin{tabular}{|c|c|}
\hline درجة القبول & كرونباخ \\
\hline مناز & $\cdot, .9 \alpha \geq$ \\
\hline جيد & $\cdot, q>\alpha \geq \cdot, v$ \\
\hline مقبول & $\cdot, v>\alpha \geq \cdot, 7$ \\
\hline ضعيف & $\cdot, 7>\alpha \geq \cdot, 0$ \\
\hline غير مقبول & $\cdot, 0>\alpha$ \\
\hline
\end{tabular}

منهجية الجانب العملى (الدراسة التطبيقية): في البداية قامت الباحثة بتحديد درجة

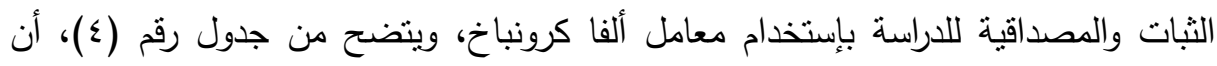
درجة الثبات 9VV, · وهي درجة مرتفعة، وإنعكس ذللك على درجة المصداقية الني بلغت

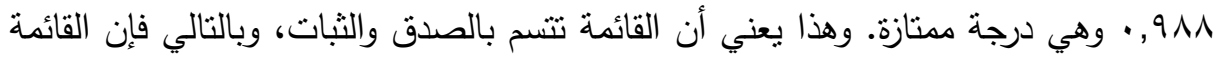

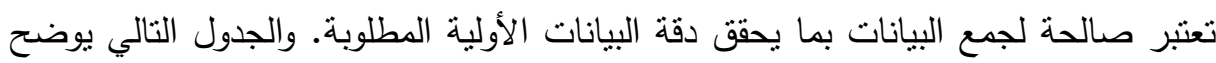
قيم معاملات الثبات والصدق لكل مجموعة عبارات. 
جدول ( §): يوضح معامل الثبات والصدق

\begin{tabular}{|c|c|c|}
\hline معامل الصدق - مع - معل & معامل الثبات & البيان \\
\hline $.69 \cdot 1$ & .6904 & تفعيل نظام الرقابة الداخلية في الشركات الصناعية \\
\hline .694 & .6970 & ترشيد الأداء البيئى في الثركات الصناعية \\
\hline. . \१9 & .6975 & الإلتزام بالمسئولية الإجتماعية لدى العاملين \\
\hline .6900 & $.69 \mathrm{VV}$ & الالكتزام بقانون حماية البيئة للحد من ظاهرة التلوث البيئي \\
\hline. $.9 \mathrm{VV}$ & $.69 \wedge \wedge$ & 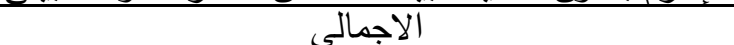 \\
\hline
\end{tabular}

Spss المصدر : من مخرجات برنامج

أولاً: وصف عينة الدراسة طبقاً للخصائص الديموجرافية

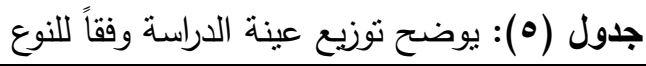

\begin{tabular}{|c|c|c|}
\hline النسبة \% & ك & النوع \\
\hline$q \cdot, \xi$ & Vo & ذكور \\
\hline 9,7 & $\Lambda$ & إناث \\
\hline $1 \ldots$ & $\Lambda \Gamma$ & الاجمالي \\
\hline
\end{tabular}

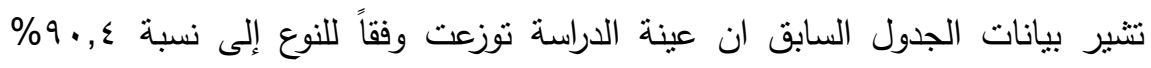

للاكور ونسبة 7 و للاناث. جدول (†): يوضح نوزيع عينة الدراسة وفقاً للعمر

\begin{tabular}{|c|c|c|}
\hline النسبة \% & ك & الفئة العمرية \\
\hline 9,7 & $\Lambda$ & آقل من · r سنة \\
\hline$r, r$ & YT & من • r-أقل من • ؛ سنة \\
\hline 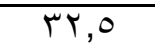 & TV & من • ع- أقل من 0کسنة \\
\hline$r \uparrow, 0$ & TY & من ·0 سنة فاكثر \\
\hline $1 \ldots$ & $\Delta \Gamma$ & الاجمالى \\
\hline
\end{tabular}

يوضح الجدول رقم (†) توزيع عينة الدراسة البالغ عددها (r/) استمارة تم توزيعها بنسبة

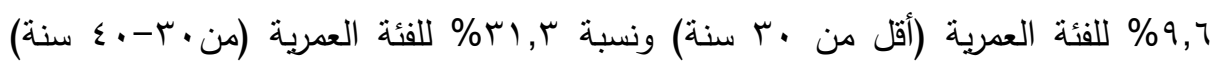

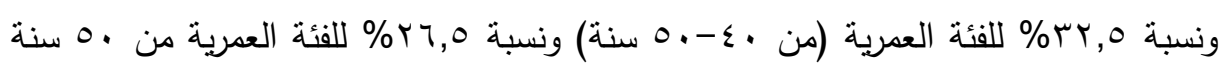
فأكثر . 
جدول (V): يوضح نوزيع عينة الدراسة وفقا لطبيعة العمل

\begin{tabular}{|c|c|c|}
\hline النسبة \% & ك & العقل \\
\hline $1 \wedge, 1$ & 10 & إدارة عليا(مدير نتفيذي) \\
\hline$\varepsilon \Lambda, Y$ & $\varepsilon$. & مسئول مالى \\
\hline$r \mu, V$ & TA & الموارد البشرية \\
\hline $1 \ldots$ & NT & الاجمالى \\
\hline
\end{tabular}

تثير بيانات الجدول السابق أن عينة الدراسة وزعت وفقاً لطبيعة العمل إلى نسبة

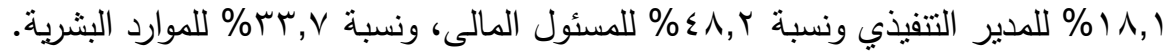
جدول (^): يوضح توزيع عينة الدراسة وفقا للمؤهل

\begin{tabular}{|c|c|c|}
\hline النسبة\%\% & s & المؤهل \\
\hline$r, \xi$ & r & درجة د كتوراه \\
\hline$V, Y$ & 7 & درجة ماجستير \\
\hline $9 \cdot, \varepsilon$ & Vo & مؤهل جامعى \\
\hline $1 \ldots$ & $\Lambda \Gamma$ & الاجمالى \\
\hline
\end{tabular}

تثتير بيانات الجدول السابق أن عينة الدراسة وزعت وفقاً للمؤهل إلى نسبة ؟ ؟r\% لدرجة

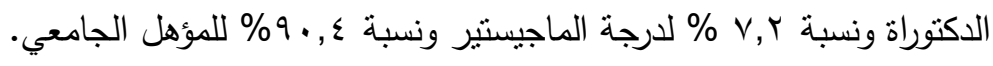

جدول (9): يوضـح توزيع عينة الدراسة طبقاً لسنوات الخبرة الوظيفية

\begin{tabular}{|c|c|c|}
\hline النسبة\%\% & 5 & الفئة \\
\hline$Y, \Sigma$ & T & آقل من ه سنوات \\
\hline$r \wedge, 9$ & TE & من هإلى آقل من · ا سنوات \\
\hline $7 \wedge, \vee$ & ov & من · (فأكثر \\
\hline $1 \cdots$ & $\Lambda \mu$ & 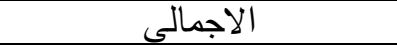 \\
\hline
\end{tabular}

تشير بيانات الجدول السابق أن عينة الدراسة وزعت وفقاً لسنوات الخبرة إلى نسبة

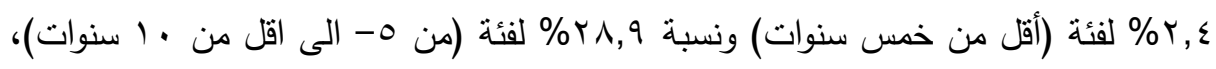

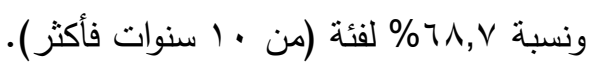


مجلة العلوم البيئية

معهد الدراسات والبحوث البيئية - جامعة عين شمس لئ

جدول ( • 1): يوضح أراء عينة الدراسة في تفعيل نظام الرقابة الداخلية فى الثركات الصناعية

\begin{tabular}{|c|c|c|c|c|c|}
\hline الإتجاه & الإتفاق & الإختلاف & الإلمعياري & المتوسط & 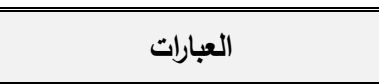 \\
\hline موافق بشدة & $V \vee, \cdot$ & $r r, \cdot$ & $1, \cdot 1$ & $\varepsilon, r q$ & 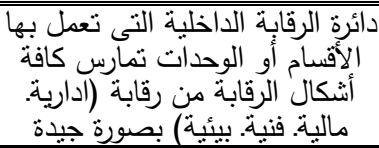 \\
\hline موافق بشدة & Nr,o & 17,0 & $\cdot, \vee \vee 7$ & $\varepsilon, 7$. & 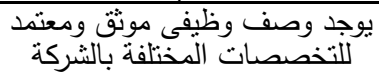 \\
\hline موافق بشدة & $\Lambda r, 0$ & 17,0 & 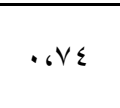 & $\varepsilon, \varepsilon \wedge$ & 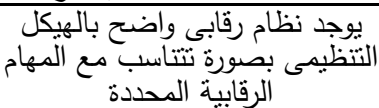 \\
\hline موافق بشدة & 10, & 10, & $\cdot, 70$ & צו & عدم وجود تداخل للسلطات \\
\hline 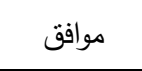 & $\wedge \varepsilon, \Gamma$ & $10, V$ & $\cdot, 70$ & $\varepsilon, 10$ & لأساليب الرقابة الداخلية مبالثركة تدابية \\
\hline 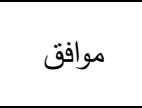 & $\Delta r, q$ & $1 V, 1$ & $\cdot, 79$ & $\varepsilon, \cdot \varepsilon$ & يوالإجراءات اللتزام من المعلقة بنظام الرّابابة \\
\hline موافق بشدة & $\Lambda r, \Lambda$ & $I V, r$ & $\cdot, \vee \vee$ & $\varepsilon, \Gamma$. & للإدارة العليا وعى كافي بأهمية \\
\hline موافق بشدة & $\wedge, \wedge$ & $1 \wedge, r$ & $\cdot, \vee \vee T$ & $\varepsilon, 1 V$ & الضوخداء الناتج على مستوى عملية \\
\hline موافق & $\vee 9,9$ & $r \cdot, l$ & •, & $\varepsilon, 1\}$ & يوجد مراجعة فلي انبعاثات الآتربة \\
\hline 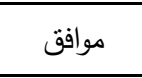 & $\Lambda \cdot, 0$ & 19,0 & $\cdot, \vee \vee 9$ & $\varepsilon, .0$ & المواد الصلبة رقابة على التخطص بصورة أنّنة \\
\hline 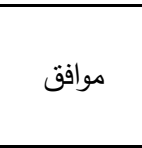 & $\vee \wedge, 0$ & Y),0 & $\cdot, \wedge 7$ & $\varepsilon, \cdots$ & 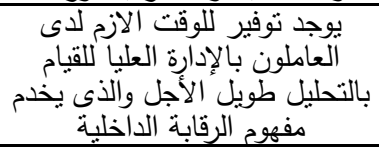 \\
\hline 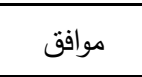 & $\vee \vee, \varepsilon$ & $r r, T$ & $\cdot, 94$ & $\varepsilon, \cdot V$ & بوجد مراجعة التخلصم المواد الصلبة \\
\hline 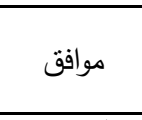 & $V\urcorner, \varepsilon$ & T & $\cdot, 91$ & $\varepsilon, 10$ & 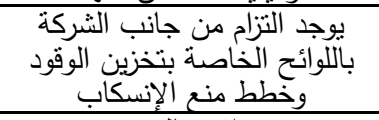 \\
\hline موافق بشدة & $\wedge 7, \vee$ & $1 \%, r$ &., 07 & $\varepsilon, Y Y$ & الاجمالى \\
\hline
\end{tabular}

يتضح من بيانات الجدول السابق ان اتجاه اجابات عينة الدراسة في الموافقة على تفعيل

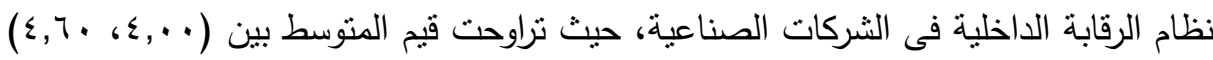

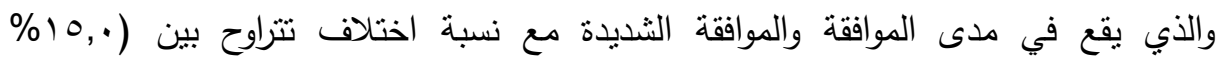

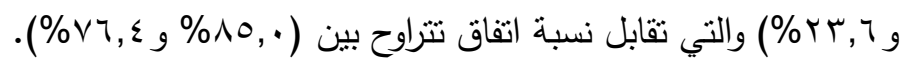

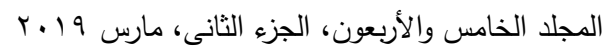


جدول (11): يوضح أراء عينة الدراسة في ترشيد الأداء البيئى فى الشركات الصناعية

\begin{tabular}{|c|c|c|c|c|c|}
\hline الإتجاه & الإتفاق & الإختلاف & المعياري & المتوسط & 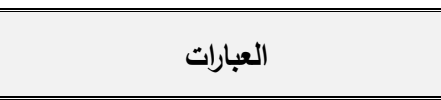 \\
\hline موافق بشدة & $\Delta r,$. & $1 \Lambda,$. & $\cdot, \vee \vee$ & $\varepsilon, r q$ & ترشيد الأداء البيئي بساعد الثركة على إليهي \\
\hline موافق بشدة & $\mid \Lambda, 1$ & 17,0 & $\cdot, \wedge$. & $\varepsilon, \varepsilon 1$ & 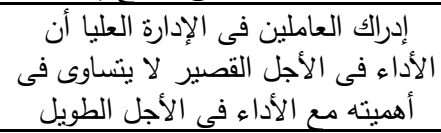 \\
\hline 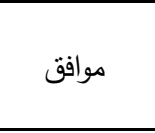 & $V Y, \Lambda$ & $r, r, r$ & $\cdot, 10$ & r,Ar & 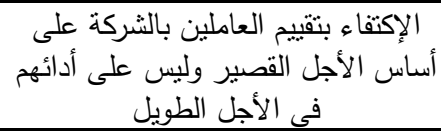 \\
\hline 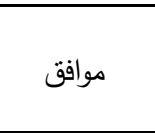 & $\wedge 1,1$ & 11,9 & $\cdot, \vee \vee 9$ & $\varepsilon, \mid V$ & والألات والمدثة باستمبرات بالتكنولوجيا المتل تطوير \\
\hline موافق بشدة & $\Delta r, 1$ & $1 v, q$ & $\cdot, \mathrm{\vee} \wedge$ & $\varepsilon, r_{0}$ & تتمتع الشركة بعوامل بيئية داخلية قوية \\
\hline 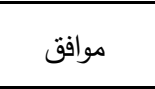 & $\wedge \varepsilon$, & $17, \cdot$ & $\cdot$, TV & $\varepsilon, 11$ & ترشيد الأداء يسهم في رفع مستوى دخل \\
\hline موافق بشدة & $\Lambda \uparrow, \Lambda$ & $17, \mathrm{r}$ & $\cdot, 7 \wedge$ & $\varepsilon, r$. & 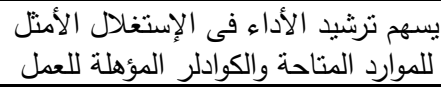 \\
\hline موافق بشدة & $\Lambda \uparrow, \Lambda$ & $I V, r$ & $\cdot, \mathrm{V} r$ & $\varepsilon, r_{0}$ & 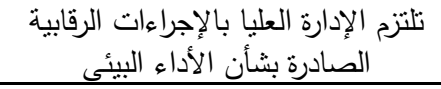 \\
\hline موافق بشدة & $\lambda \cdot, v$ & $19, r$ & $\cdot, \wedge)$ & $\varepsilon, r$. & الإدارة العليا تلبيى منطلبات الألتاء البئية \\
\hline موافق بشدة & ^r, & $17, \varepsilon$ & $\cdot, v$. & $\varepsilon, Y \wedge$ & يوجد إهتمام من جأنب الإدارة العليا البيأئي \\
\hline موافق بشدة & $A r, 1$ & $1 v, q$ & $\cdot, \mathrm{V}$ & $\varepsilon, Y_{O}$ & 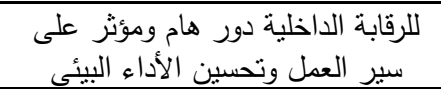 \\
\hline موافق بشدة & $\wedge r, \lambda$ & $17, \mathrm{r}$ & $\cdot, 7 \uparrow$ & $\varepsilon, r)$ & 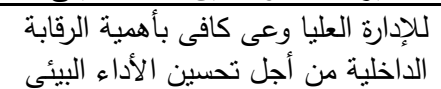 \\
\hline موافق بشدة & $\wedge 7,0$ & $1 \pi, 0$ &., $0 \mathrm{~V}$ & $\varepsilon, \pi T$ & الاجمالى \\
\hline
\end{tabular}

يتضح من بيانات الجدول السابق أن إتجاه إجابات عينة الدراسة فى الموافقة على ترشيد

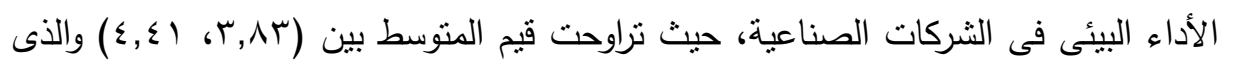

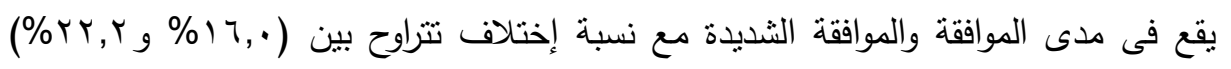

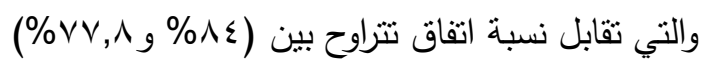


مجلة العلوم البيئية

معهد الدراسات والبحوث البيئية - جامعة عين شمس له

\begin{tabular}{|c|c|c|c|c|c|}
\hline الإتجاه & معامل & الإختلاف معلف & الإنحراف & المرجح & العبارات \\
\hline موافق بشدة & $\wedge \uparrow, 1$ & $1 \pi, 9$ & זד, • & $\varepsilon, O Y$ & 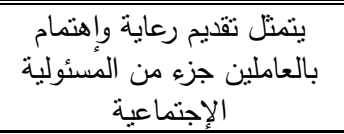 \\
\hline موافق بشدة & $\Lambda \varepsilon, Y$ & 10,1 & $\cdot, 7 \wedge$ & $\varepsilon, \Gamma$. & الإلتزام بالمسئولية الإجتماعية على البئة \\
\hline موافق & $17, v$ & $\cdot, \vee \cdot$ & $\cdot, 10$ & $\varepsilon, 11$ & 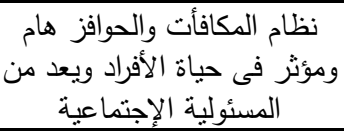 \\
\hline موافق & $\Lambda, r$ & $1 \wedge, \vee$ & $\cdot, \vee \vee 90$ & $\varepsilon, \cdot r$ & يوجد تأمين صحى لجميع \\
\hline موافق & NT, & 17,1 & $\cdot, 79$ & $\varepsilon, 1$. & يوجلابس وسائل سلامة لعمال مهنبة، من الشركة \\
\hline موافق بشدة & $\wedge \varepsilon, q$ & 10,1 & $\cdot, 70$ & $\{, r)$ & 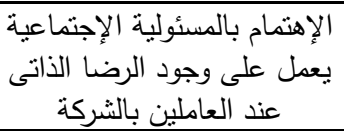 \\
\hline موافق & 10,9 & $1 \leqslant, 1$ & $\cdot, 09$ & $\varepsilon, 19$ & 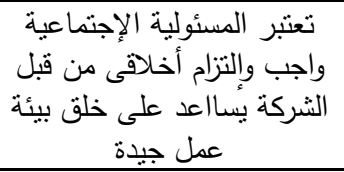 \\
\hline موافق بشدة & $\wedge \vee, \Lambda$ & $M, r$ & $\cdot, 0 Y$ & $\varepsilon, 19$ & فتى حالة إصابة الثركة أحدافات العاملين الأولية \\
\hline موافق بشدة & $\Lambda \vee, \Lambda$ & $M, r$ & .,OY & $\varepsilon, Y_{T}$ & الإجمالى \\
\hline
\end{tabular}

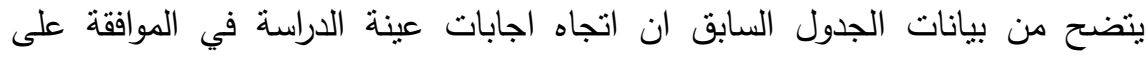

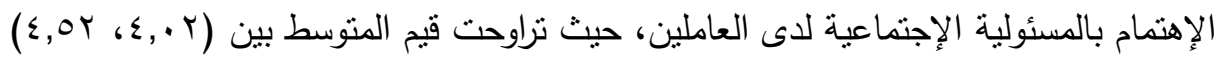

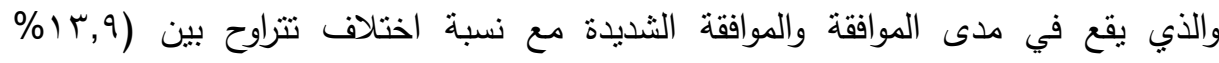

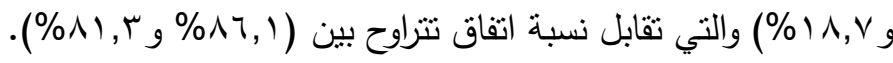


جدول (r ( )): يوضح أراء عينة الدراسة في الإلتزام بقانون حماية البيئة للحد من ظاهرة التلوث

\begin{tabular}{|c|c|c|c|c|c|}
\hline 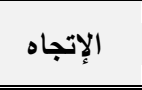 & الإتفاق & الإختلاف معامل & الإنحراف & المتوسط & 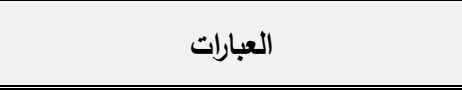 \\
\hline موافق بشدة & 10,7 & $1 \varepsilon, \varepsilon$ & $\cdot, 74$ & $\varepsilon, 09$ & تحتفظ الثركة بسجل لبيان مدى نأثير \\
\hline موافق بشدة & $\wedge \varepsilon, r$ & 10,1 & $\cdot, \times 1$ & $\varepsilon, \varepsilon q$ & 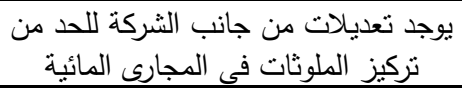 \\
\hline موافق بشدة & ヘr, ๕ & 17,7 & $\cdot$ • $V \leq$ & $\varepsilon, \varepsilon 0$ & 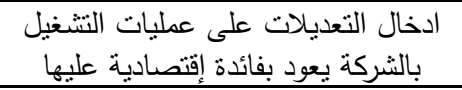 \\
\hline 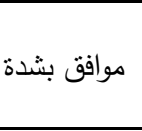 & $\wedge r, \wedge$ & $I V, r$ & $\cdot, \mathrm{VV}$ & $\varepsilon, \Sigma \vee$ & فتى عملية التصنيع بدكة السولار أو الغاز الطبيعى المازوت للحد \\
\hline موافق بشدة & $\Delta r, r$ & $I V, \Lambda$ & $\cdot, \wedge$. & $\varepsilon, \varepsilon q$ & تلتزم الثركة بقانون ؟ لسنة ـ99 الحفاظ من البيئة وسلامتها \\
\hline 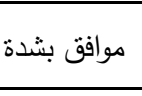 & $\wedge, \varepsilon$ & $1 \wedge, 7$ & $\cdot, \lambda r$ & $\varepsilon, \varepsilon$. & تستخدم الشركة تقنيات أحدث أُاستبيدال \\
\hline موافق بشدة & $\wedge, r$ & 17,8 & $\cdot, V T$ & $\varepsilon, \Gamma V$ & 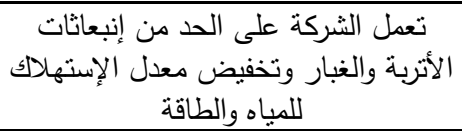 \\
\hline 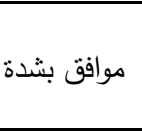 & $\wedge, \vee \vee$ & iᄉ,r & $\cdot, \mathrm{VV}$ & $\varepsilon, r$ & 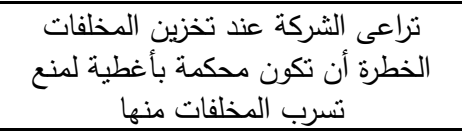 \\
\hline 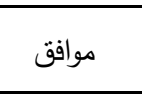 & $\wedge 1,7$ & \, 乏 & $\cdot, \mathrm{VV}$ & $\varepsilon, 19$ & 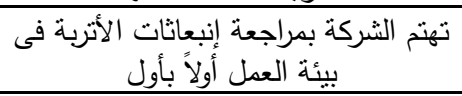 \\
\hline 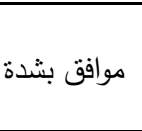 & $\wedge r, q$ & $\mid V, 1$ & $\cdot, \mathrm{V}$ & $\varepsilon, Y V$ & 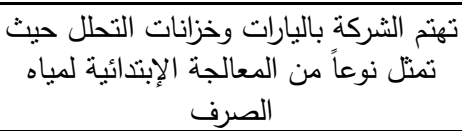 \\
\hline 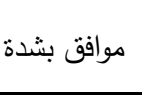 & $\wedge, \wedge$ & $1 \wedge, r$ & $\cdot, \vee \vee 9$ & $\varepsilon, \Upsilon \wedge$ & تلتزم الشركة بالإشتراطات الخاصنة التى حداز \\
\hline موافق بشدة & $\wedge 0, \wedge$ & $1 \varepsilon, r$ & $\cdot, T Y$ & $\varepsilon, \Gamma \wedge$ & الاجمالي \\
\hline
\end{tabular}

يتضح من بيانات الجدول السابق أن إتجاه إجابات عينة الدراسة في الموافقة على الى

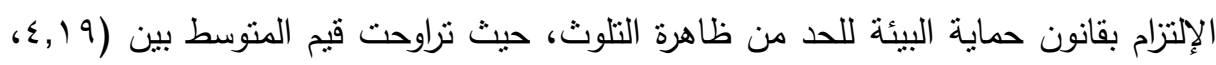

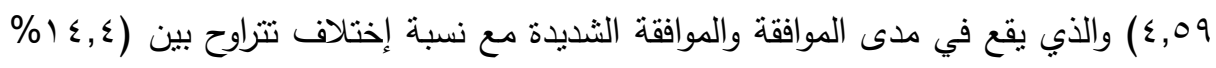

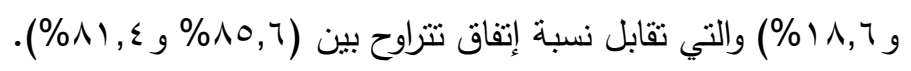




\section{إختهار سهلة هروض الصراسة}

الفرض الأول: لا نوجد علاقةجوهرية بين تفعيل نظام الرقابة الداخلية وترشيد الأداء البيئي

$$
\text { فى الثركات الصناعية. }
$$

الفرض الثاني: لا نوجد علاقة جوهرية بين تفعيل نظام الرقابة الداخلية فى الثركات

$$
\text { الصناعية والإهتمام بالمسئولية الإجتماعية لاى العاملين. }
$$

الفرض الثالث: لا توجد علاقة جوهرية بين ترشيد الأداء البيئي والإهنمام بالمسئولية

$$
\text { الإجتماعيةفى الثركات الصناعية. }
$$

الفرض الرابع: لا توجد علاقة جوهرية بين تفعيل نظام الرقابة الداخلية فى الثركات

الصناعية والإلتزام بقانون حماية البيئة للحد من ظاهرة التلوث البيئي.

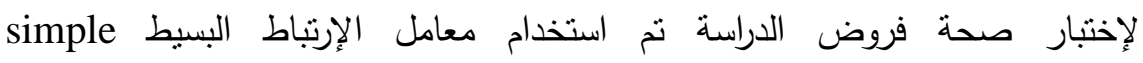

$$
\begin{aligned}
& \text { correlation coefficient } \\
& \text { المتغير التابع: ترشيد الأداء البيئى فى الثركات الصناعية }
\end{aligned}
$$

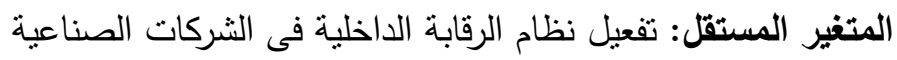


جدول (؛ (): يوضح نتائج تحليل إنحدار المتغيرات الدالة على تفعيل نظام الرقابة فى

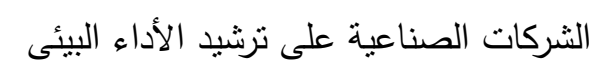

\begin{tabular}{|c|c|c|c|c|c|c|c|}
\hline التحديد & الإرتباط & الدلالةي & قيمة"ف" F & الدلالةي & قيمة & الإنحدار & \\
\hline \multirow{5}{*}{$\cdot \triangleleft \wedge \vee V$} & \multirow{5}{*}{. .949 } & \multirow{5}{*}{$\cdots$} & \multirow{5}{*}{$1 \leq 7,09$} & 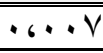 & $Y, V V$ & $\varepsilon, \varepsilon\rceil \xi$ & الثابت \\
\hline & & & & ...r) & r, ro & .6119 & مسوجت مراجعة الضوضلى التكسبر عن عملية \\
\hline & & & & . & $7, \leqslant 7$ & $\cdot 6 \leq 7$ & ولئيفى موثنق \\
\hline & & & & . & $\Lambda, Y_{0}$ & • r r & إنبعاثات مراجعة الأتربة على \\
\hline & & & & . 6. & $\varepsilon, 9 \leqslant$ & $\cdot, 197$ & 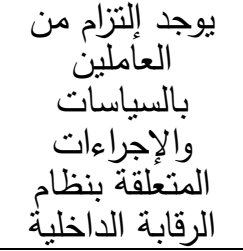 \\
\hline
\end{tabular}

يتضح من بيانات الجدول السابق معنوية نموذج الإنحدار عند مستوى دلالة أقل من

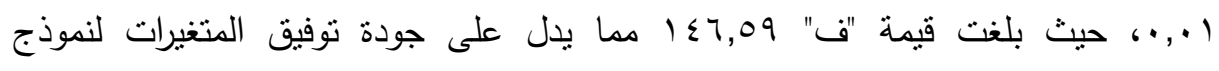
الإنحدار 
جدول (10): يوضح نتائج تحليل إنحدار المتغيرات الدالة على تفعيل نظام الرقابة فى

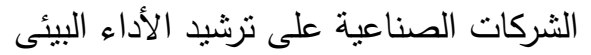

\begin{tabular}{|c|c|c|c|c|c|c|c|}
\hline التحديد & الإرتباط & الدلالة & قيمة"ف" F & الدستوي & قيمة ت & $\begin{array}{c}\text { الإحدار } \\
\text { معامل } \\
\end{array}$ & \\
\hline \multirow{4}{*}{. $6 V T V$} & \multirow{4}{*}{. “人Tร } & \multirow{4}{*}{. . . . } & \multirow{4}{*}{$v 0,79$} & $\cdots \ldots$ & $7, \vee 74$ & . & الثابت \\
\hline & & & & $\cdots \cdots$ & $\lceil, \Lambda)$ & $.6 \% 01$ & لموند وصف ومعتمد وظيفى \\
\hline & & & & $\cdots \ldots$ & $r, q 1$ & .6109 & 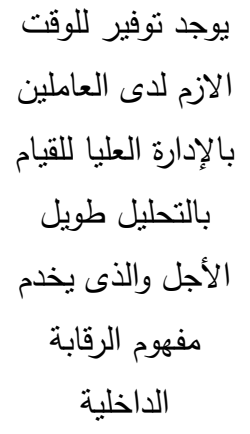 \\
\hline & & & & $\cdots \cdots$ & $r, \wedge 0$ & •, ror & 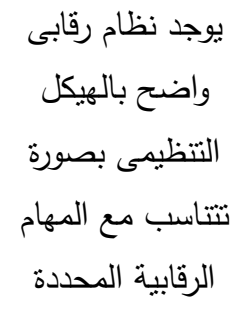 \\
\hline
\end{tabular}

يتضح من بيانات الجدول السابق معنوية نموذج الإنحدار عند مستوى دلالة اقل من

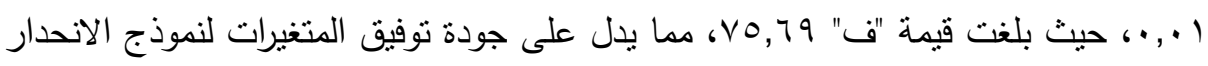

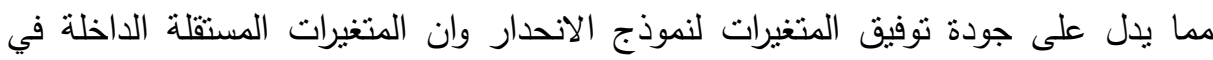
النموذج (يوجد وصف وظيفى موثق ومعتمد للتخصصات المختلفة بالثركة). 


\section{النجمانs \\ أولاً: نتائج خاصة بمتغيرات الدراسة \\ نتائج خاصة بتفعيل نظام الرقابة الداخلية فى الشركات الصناعية: \\ أثنتت الدراسة:}

• أن دائرة الرقابة الداخلية التى تعمل بها الأقسام أو الوحدات تمارس كافة أثنكال الرقابة من

رقابة (ادارية، مالية، فنية، بيئية) بصورة جيدة، وانه يوجد وصف وظيفى موثق ومعتمد

$$
\text { للتخصصات المختلفة بالثركة. }
$$

• وجود نظام رقابى واضح بالهيكل التظيمى بصورة تتتاسب مع المهام الرقابية المحددة مع بـ

عدم وجود تداخل للسلطات والمسئوليات، مع وجود مهارات تدريبية مناسبة لأساليب الرقابة

الداخلية بالثركة مع إلتزام من العاملين بالسياسات والإجراءات المتعلقة بنظام الرقابة

الداخلية.

نتائج خاصة بترشيا الأداء البيئى فى الشركات الصناعية:

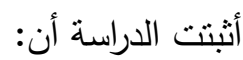

• ترشيد الأداء البيئى يساعد الثركة على تحقيق أهدافها التى تطمح اليها ويسهم في

الإستغلال الأمتل للموارد المتاحة والكوادر المؤهلة للعمل.

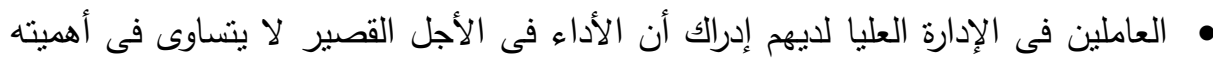

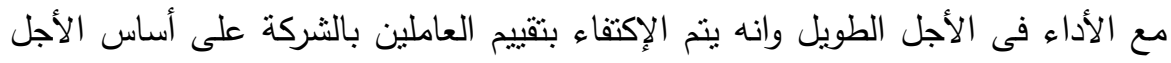

$$
\text { القصير وليس على أدائهم فى الأجل الطويل. }
$$

نتائج خاصة بالإهتمام بالمسئولية الإجتماعية لاى العى العاملين:

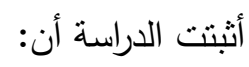

• تقديم الرعاية والإهتمام بالعاملين جزء من المسئولية الإجتماعية، لان الالتزام بالمسئولية

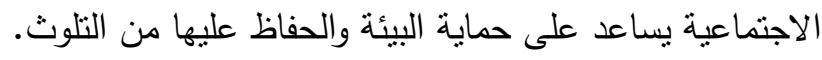

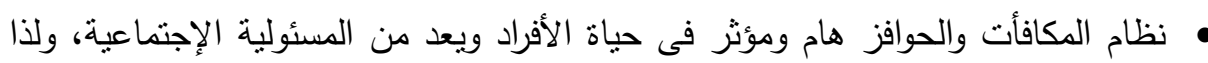

$$
\text { يجب ان وجود تأمين صحى لجميع موظفين الثركة. }
$$

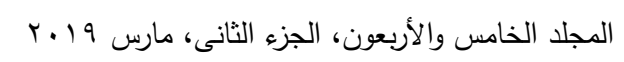




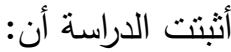
• الثركة تحتفظ بسجل لبيان مدى تأثنير نشاطها على البيئة. • وجود تعديلات من جانب الشركة للحد من تركيز الملوثات فى المجارى المائية. • ادخال التعديلات على عمليات التتغيل بالثركة يعود بفائدة اقتصادية عليها. ثانياً: نتائج خاصة بصحة فروض الدراسة: قامت الدراسة على أربعة فروض رئيسية

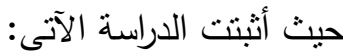
عدم صحة الفرض القائل: لا توجد علاقة طردية بين تفعيل نظام الرقابة الداخلية وترشيد الأداء البيئي فى الثركات الصناعية. عدم صحة الفرض القائل: لا نوجد علاقة طردية بين تفعيل نظام الرقابة الداخلية فى الشركات الصناعية والإهنمام بالمسئولية الإجتماعية لدى العاملين. عدم صحة الفرض القائل: لا نوجد علاقة طردية بين ترشيد الأداء البيئي والاهتمام بالمسئولية الاجتماعية فى الشركات الصناعية. عدم صحة الفرض القائل: لا توجد علاقة طردية بين تفعيل نظام الرقابة الداخلية فى الثركات الصناعية والإلتزام بقانون حماية البيئة للحد من ظاهرة التلوث البيئي.

\section{الميوكياتص}

في ضوء نتائج الدراسة توصى الباحثة بما يلى:

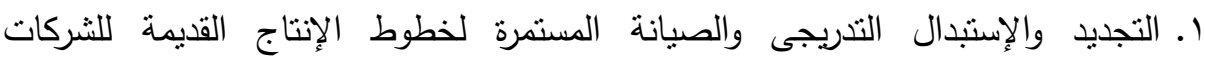

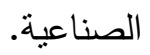
r. ضرورة إنشاء إدارة بيئية فى كل شركة صناعية وذلك لمتابعة المعايير والثروط المسموح

$$
\text { بها وذللك للحد من التلوث البيئى. }
$$

r. تبنى مبدأ ندوير المخلفات والإستفادة منها وذلك لتحقيق عائد مادى للشركات الصناعية. ع. الإهتمام بعمل محطات رصد ألى لصد كمية الغبار العالق بالجو فى المناطق المحيطة

بالشركة وذلك لإمكانية قياس كمية الجسيمات الدقيقة المنبعثة والعمل على معالجتها.

$$
\text { المجلد الخامس والأربعون، الجزء الثانى، مارس } 19
$$


0. العمل على توسيع رقعة الغطاء النباتى من أجل بيئة خضراء.

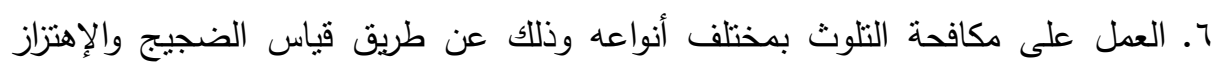
لمناطق الثركة الصناعية والمناطق المحيطة بها ومطابقة هذه القياسات بالمواصفات

العالمية.

\section{المرامئم}

أبو قحف، عبد السلام (990 (م): أساسيات الإدارة، الدار الجامعية للنشر ، بيروت.

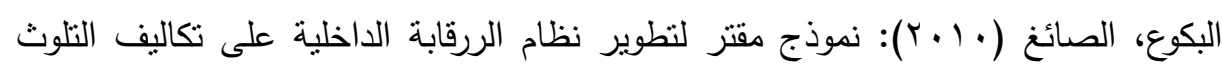
البيئى للشركة العالمية للأسمنت الثمالية.

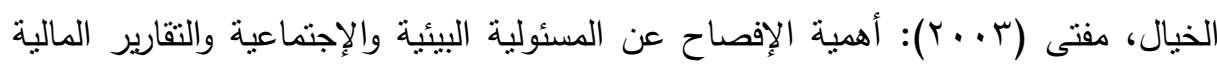
فى المملكة العربية السعودية.

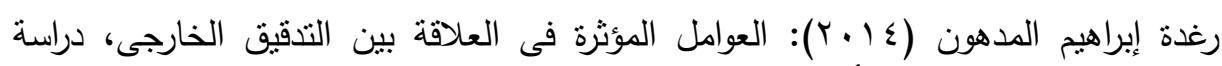

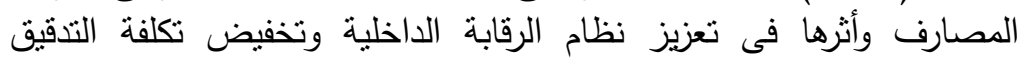
الخارجى - دراسة تطبيقية.

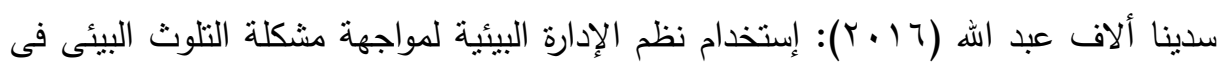
قطاع الصناعة فى ليبيا.

شاكر عبد الكريم هادى (1991)): أثز هيكل الرقابة الداخلية فى فاعلية أداء الوحدات الإقتصادية.

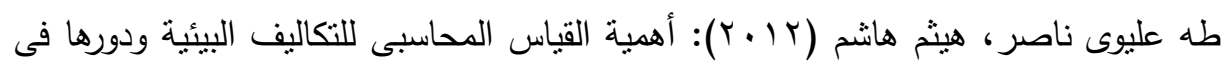

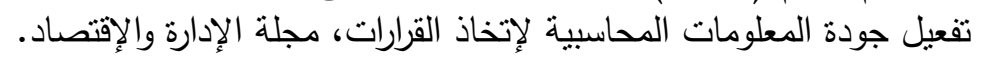

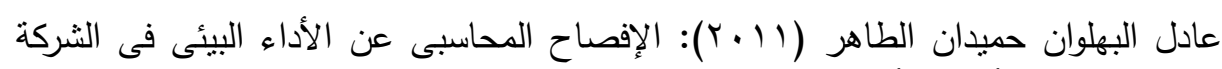
الأهلية للأسمنت بليبيا - دراسة إسنطلاعية، دكنوراه.

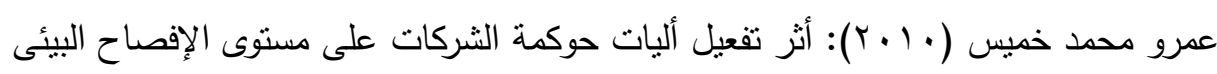
الإختيارى.

مصطفى على إبراهيم جاد الكريم (ع ا • ب): أثز الإلتزام البيئى على الإنتاج والأداء بالمنشآت

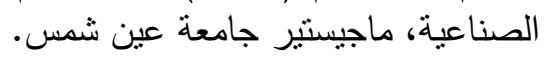


Companies in Aqaba Claudia (2013): A review of environmental monitoring and auditing in the context of risk: unveiling the extent of a confused relationship.

Kathyayini (2012): Corporate governance and environmental reporting: an Australian study. Vol. 12, Iss: 2

Mousa Saleh (2012): Environmental Disclousurein Industrial

Rombabukodali Anand Hurumurthy (2009): Application of benchmarking for assessing the learn manufacturing implementation.

\title{
ACTIVATING THE INTERNAL CONTROL SYSTEM TO RATIONALIZE THE ENVIRONMENTAL PERFORMANCE AN APPLIED STUDY ON CEMENT FACTORIES
}

\author{
Eman M. Z. Adam ${ }^{(1)}$; Khalid H. Ahmed ${ }^{(2)}$; \\ Salah A. Abu El- Enain ${ }^{(3)}$ and Kareem M. Gohar ${ }^{(2)}$ \\ 1) Ministry of Education 2) Faculty of Commerce, Ain Shams \\ University 3) Faculty of Sciences, Ain Shams University
}

\begin{abstract}
There is increasing interest on the part of the state to protect the environment from the harmful effects of cement companies in Egypt. They have been associated with pollution of the environment and the resulting damage. The most affected are individuals living in industrial zones and suffering from severe chest diseases May lead to their lives from the severity of gravity.
\end{abstract}

$$
\text { المجلد الخامس والأربعون، الجزء الثانى، مارس } 19
$$


The aim of this study was to identify the most important procedures for activating internal control for the purpose of environmental performance and to determine the relationship between activating internal control systems and rationalizing environmental performance. To achieve this goal, the researchers relied on theoretical rooting through the extrapolative approach of Arabic and foreign books, references and studies. Therefore, the main motive for conducting this study was the necessity of activating internal control to rationalize environmental performance in order to preserve the environment. The sample of the study in the cement factories and the number of 6 companies out of 19 companies in Egypt were collected data, The forms were distributed at the levels of financial managers and accountants to 105 of the levels mentioned in those companies.

The study reached the most important results: Environmental compliance with legal requirements and standards is a value in itself for the protection of the environment. Industry is the mainstay of raising economic growth rates. Environmental compliance must be carried out through a theoretical framework that uses the concepts of internal control and rationalization and measurement of environmental performance. The study recommended the establishment of environmental management in each industrial company to follow the standards and conditions allowed to reduce environmental pollution. 